This item was submitted to Loughborough's Research Repository by the author.

Items in Figshare are protected by copyright, with all rights reserved, unless otherwise indicated.

\title{
Application of the discrete transfer model of thermal radiation in a CFD simulation of diesel engine combustion and heat transfer
}

PLEASE CITE THE PUBLISHED VERSION

PUBLISHER

(C) Society of Automotive Engineers

VERSION

NA (Not Applicable or Unknown)

\section{LICENCE}

CC BY-NC-ND 4.0

\section{REPOSITORY RECORD}

Blunsdon, C.A., W. Malalasekera, and John C. Dent. 2019. "Application of the Discrete Transfer Model of Thermal Radiation in a CFD Simulation of Diesel Engine Combustion and Heat Transfer". figshare. https://hdl.handle.net/2134/5750. 
This item was submitted to Loughborough's Institutional Repository (https://dspace.lboro.ac.uk/) by the author and is made available under the following Creative Commons Licence conditions.

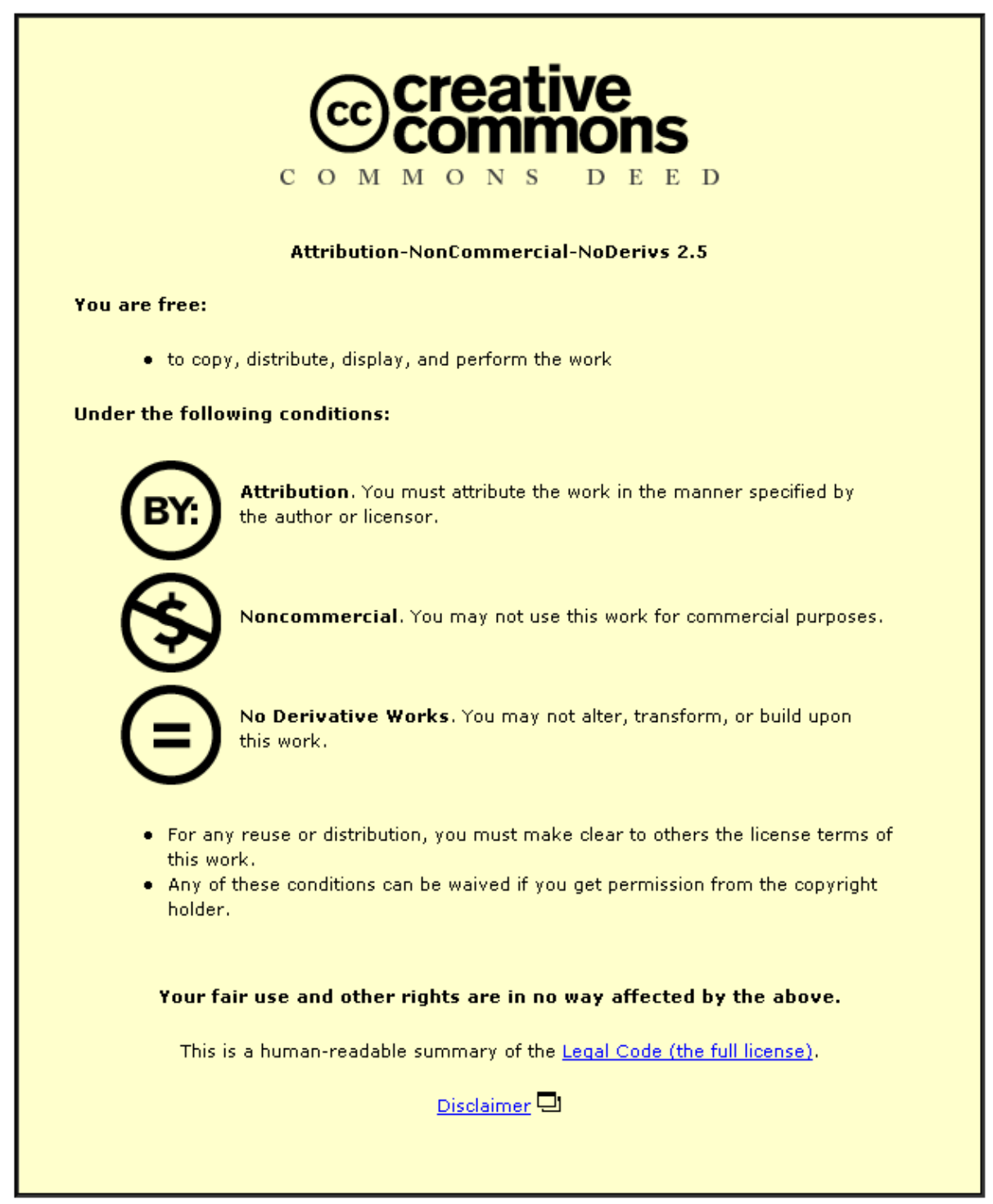

For the full text of this licence, please go to: http://creativecommons.org/licenses/by-nc-nd/2.5/ 


\title{
Application of the Discrete Transfer Model of Thermal Radiation in a CFD Simulation of Diesel Engine Combustion and Heat Transfer
}

\author{
Blunsdon, C. A., Malalasekera W. M. G. and Dent J.C. \\ Department of Mechanical Engineering \\ Loughborough University of Technology, Loughborough, \\ Leicestershire LE11 3TU, UK.
}

\begin{abstract}
This paper describes the application of the discrete transfer model of thermal radiation in the engine CFD code KIVA for the simulation of diesel combustion and heat transfer. The comprehensive modelling of flows and heat transfer in engines requires accurate evaluation of transient temperature and radiation properties of the gaseous combustion products. A submodel for autoignition chemistry and a soot formation and oxidation model have been incorporated in the general computational fluid dynamics procedure, and Hottel's mixed grey and clear gas concept has been used to evaluate emissivities. Results of calculations are presented for engine aerodynamics, cylinder pressure and temperature, soot concentration, and radiative heat fluxes. Radiative heat fluxes have been compared with data, in similar experimental engines. Comparisons between the predictions and data show encouraging agreement. Inclusion of the submodels for autoignition and soot formation and combustion seem to have greatly enhanced radiation predictions. It is concluded that present prediction techniques can be useful in providing information in engine flows under a variety of engine operating conditions.
\end{abstract}

\section{INTRODUCTION}

The demand for highly efficient compact engines makes accurate evaluation of instantaneous local heat transfer important in defining engine durability and thermal efficiency.

In diesel engines, heat transfer from combustion gases to cylinder walls is by a combination of convective and radiative modes.

Thermal radiation can occur in specific wave length bands as non luminous gaseous emission due to changes with temperature of the vibrational and rotational energy states of heteropolar molecules such as $\mathrm{CO}, \mathrm{CO}_{2}$ and $\mathrm{H}_{2} \mathrm{O}$. It also occurs as a continuous luminous emission in a combustion process due to presence of incandescent carbon particles.

In diesel engines, luminous emission is controlled by local instantaneous temperature and carbon (soot) concentration in the flame volume and the disposition of this volume relative to the surfaces of the combustion space. Therefore, a need for the incorporation of a general radiation heat transfer model into engine Computational Fluid Dynamics (CFD) codes exists.

\section{SUB MODELS}

MODIFICATIONS TO THE KIVA CODE - The CFD code KIVA has been developed for the finite volume numerical computation of transient, three dimensional, chemically reactive fluid flows with injected sprays in engine geometries and has been widely reported in the literature ${ }^{1-4}$. For brevity it will not be reviewed here.

In order to simulate increases in radiative heat flux observed during autoignition ${ }^{5}$, it is necessary to incorporate a suitable model for autoignition in the original KIVA code. Similarly, suitable soot formation and oxidation sub-models need addition to the original code for use in the Discrete Transfer Radiation model, discussed later in the paper. In order to better describe the fuel jet/combustion chamber wall interaction in the swirl assisted diesel engine, the submodel for the wall jet according to Naber and Reit $z^{6}$ was incorporated into the code.

AUTO-IGNITION SUBMODEL AND MIXING CONTROLLED COMBUSTION - In diesel engines fuel is injected through a multi-hole nozzle over a few milliseconds, into compressed high temperature swirling air. Rapid atomisation, evaporation and mixing of part of the fuel at the edges and in the wake 
of the fuel sprays occurs. In these high temperature zones thermo-kinetic reactions progress to autoignition with consequent release of thermal energy to sustain the main combustion of fuel and air, which is mixing limited.

In the original KIVA code, turbulent mixing within the finite volume cell structure is defined by the $k-\varepsilon$ model of turbulence, which provides an adequate description of turbulent transport on a scale comparable to the finite volume cell representation. However, it gives no information concerning transport processes at the Kolmogorov scale, where reactions are considered mixed to near molecular levels in a fine structure of the flow field where reaction chemistry is fast. This structure occupies a volume which is a small fraction of that of the complete flow. Following Chomiak $^{7}$ and Magnussen ${ }^{8}$ the mass fraction of fluid in the fine structure is $m_{f}$, where

$$
m_{f}=\text { constant }\left(v / u^{\prime}\right)
$$

$v$ is the Kolmogorov velocity scale in the reacting fine structure, and $u^{\prime}$ the turbulence velocity. For nearly isotropic turbulence, equation (1) can be rewritten as

$$
m_{f}=A\left(v \varepsilon / k^{2}\right)^{3 / 4}
$$

where $A$ is a constant of order $10, v$ the kinematic viscosity, $\varepsilon$ the rate of turbulence energy dissipation per unit mass and time, and $k$ the turbulent kinetic energy.

In application of the autoignition sub model, we have adopted the KIVA implementation of Theobald and $\mathrm{Cheng}^{9}$, and the energy conservation formulation of Schapertons and Lee ${ }^{10}$, in the model developed by researchers at the SHELL Research Centre 11,12

The SHELL model considers autoignition reactions to proceed via a degenerate branched chain mechanism, within a thermo-kinetic framework arising from coupling between heat release and the reactions responsible for self acceleration of the process. The description of the chemical system is generic, consisting of a fuel molecule $\mathrm{RH}$ with chemical formula $\mathrm{C}_{n} \mathrm{H}_{2 m}$, total radicals $\mathrm{R}$, total Branching agent $\mathrm{B}$, a labile intermediate species $Q$ and oxidised products $P$. The eight reactions comprising the model are shown in Table 1.

The SHELL model was originally applied to autoignition (KNOCK) in two zone (burned/unburned gas) Thermodynamic models of spark ignition engines, in which transport and conservation of species within the unburned zone presented no problem. In the context of CFD applications of the model, it is necessary that mass conservation is satisfied. This has been undertaken in the manner described by Schapertons and Lee ${ }^{10}$.

At temperatures representative of those occurring towards the end of the compression stroke in
Table 1

Rate

\begin{tabular}{lll}
\hline \multicolumn{3}{l}{ Rate } \\
\hline Initiation \\
$\mathrm{RH}+\mathrm{O}_{2} \rightarrow 2 \mathrm{R}$ & $\mathrm{k}_{\mathrm{q}}$ & $(3)$ \\
\hline Propagation & & \\
$\mathrm{R} \rightarrow \mathrm{R}+\mathrm{P}$ & $\mathrm{k}_{\mathrm{p}}$ & $(4)$ \\
\hline $\mathrm{R} \rightarrow \mathrm{R}+\mathrm{B}$ & $\mathrm{f}_{1} \mathrm{k}_{\mathrm{p}}$ & $(5)$ \\
\hline $\mathrm{R} \rightarrow \mathrm{R}+\mathrm{Q}$ & $\mathrm{f}_{4} \mathrm{k}_{\mathrm{p}}$ & $(6)$ \\
\hline $\mathrm{R}+\mathrm{Q} \rightarrow \mathrm{R}+\mathrm{B}$ & $\mathrm{f}_{2} \mathrm{k}_{\mathrm{p}}$ & $(7)$ \\
\hline $\begin{array}{l}\text { Branching } \\
\mathrm{B} \rightarrow 2 \mathrm{R}\end{array}$ & & \\
$\begin{array}{l}\text { Linear Termination } \\
\mathrm{R} \rightarrow \text { Non Reactive } \\
\text { Species }\end{array}$ & $\mathrm{k}_{\mathrm{b}}$ & $(8)$ \\
\hline $\begin{array}{l}\text { Quadratic Termination } \\
2 \mathrm{R} \rightarrow \text { Non Reactive } \\
\text { Species }\end{array}$ & $\mathrm{f}_{3} \mathrm{k}_{\mathrm{p}}$ & $(9)$ \\
\hline
\end{tabular}

diesel engines, the reactive scheme above describes a two stage ignition process in which an initial ignition delay period is followed successively by a cool flame period in which temperature is approximately constant, and finally a very short period when temperature rises rapidly in a second stage of ignition. The ignition delay process is described by the degenerate branching reactions, equations (5) and (8). The second stage ignition process follows the production path of the labile intermediate $Q$, described by equations (6), (7) and (8). At higher cylinder temperatures the model gives a single stage ignition process, the cool flame constant temperature period reducing to a sharp inflexion in the temperature time history of the reactive species.

In the treatment of the post ignition combustion process Theobold and Cheng ${ }^{9}$ replace the reaction scheme (equations (3) to (10)) by a one step global kinetic scheme which becomes effective when temperatures exceed $1000 \mathrm{~K}$. The reaction is mixing limited by available fuel and oxygen. This procedure is necessary to inhibit very rapid rises in local $Q$ concentration and temperatures, which result in failure of the calculation, or the need for uneconomically small computational time steps. We have found this approach limiting when applied over a range of engine injection timings. Furthermore, we wished to adopt an 
approach compatible with the general scheme used for calculation of soot oxidation discussed later.

Hirst and Kirsch ${ }^{12}$ in discussing the application of the SHELL model to autoignition in diesel engines, consider low mixing rates to control fuel air mixing to reactive stoichiometry and temperature, (i.e. delay period) and high mixing rates to result in rapid ignition. We have attempted to implement this, by applying the SHELL reaction scheme in each computational cell at its prevailing stoichiometry, temperature and levels of $\mathrm{R}, \mathrm{B}, \mathrm{Q}$ and $\mathrm{P}$ at each computational time step.

The combustion rate per unit volume $R^{\prime \prime \prime}$ is considered mixing controlled when cell temperatures exceed $1700 \mathrm{~K}$ and following Magnussen and Hjertager $^{13}$ this may be expressed as

$$
\dot{R}^{\mathrm{m}}=B(\varepsilon / k) \min \left(\rho_{f}, \rho_{\mathrm{O}_{2}} / r\right) \quad\left(\mathrm{kg} / \mathrm{m}^{3} \mathrm{~s}\right)
$$

where $B$ is a model constant, $\rho_{f}$ and $\rho_{\mathrm{O}_{2}}$ the partial density of fuel vapour and oxygen and $r$ the stoichiometric constant of the fuel.

Autoignition in the fine structure proceeds to mixing-controlled combustion throughout the cell as follows. Let $R_{Q}$ be the rate of generation of $Q$, in mole/mole/s, and let $R_{K}$ be the characteristic mixing rate at the Kolmogorov scale $(\varepsilon / v)^{1 / 2}$. When the rate of generation of $Q$ is such that

$$
R_{\mathrm{Q}} \geq 5^{*} \mathrm{R}_{\mathrm{K}}
$$

mixing controlled combustion begins at the Kolmogorov scale, in parallel with the autoignition reactions. Following equation (11), the mixing controlled reaction rate can be expressed as

$$
\dot{R}^{\prime \prime \prime}=C(\varepsilon / v)^{1 / 2} m_{f} \min \left(\rho_{f}, \rho_{O_{2}} / r\right) \quad\left(\mathrm{kg} / \mathrm{m}^{3} \mathrm{~s}\right)
$$

where $C$ is a model constant. When $R_{Q}>20^{\star} R_{K}$ and the concentration of $Q$ in the fine structure is greater than $10^{-8} \mathrm{~mol} / \mathrm{cm}^{3}$, or the cell temperature is greater than $1700 \mathrm{~K}$, then second stage ignition is considered to have occurred, the autoignition reactions are disabled and combustion proceeds at the rate given by equation (11)

SOOT FORMATION MODEL - Our own experience of modelling soot formation in diesel engines ${ }^{14,15}$ and that of Zellat et $a^{16}$ has led us to adopt the Tesner model ${ }^{13,17}$ for incorporation into the KIVA code. This model consists of three main steps:

(1) Spontaneous formation of radicals by thermal decomposition of fuel $\left(n_{0}\right)$.

$$
n_{o}=a_{o} \rho_{f} \exp (-E / G T)
$$

(particles $/ \mathrm{m}^{3} \mathrm{~s}$ )

where $a_{o}=2.32 \times 10^{32}$ particles $/ \mathrm{kg} \mathrm{s}, \rho_{f}$ the partial density of fuel vapour $\left(\mathrm{kg} / \mathrm{m}^{3}\right), E / G$ the Activation temperature $(=90,000 \mathrm{~K})$.
(2) Nuclei formation via branching and termination processes

$\frac{d n}{d t}=n_{o}+(f-g) . n-g_{o} n . N \quad\left(\right.$ particles $\left./ \mathrm{m}^{3} \mathrm{~s}\right)(14)$ where $n$ is the concentration of nuclei (particles $/ \mathrm{m}^{3}$ ), $(f-g)$ the difference between the linear branching and termination coefficients respectively $\left(=10^{2} / \mathrm{s}\right), g_{0}$ a linear termination coefficient due to the nuclei/particle surface termination process ( $=10^{-15} \mathrm{~m}^{3} / \mathrm{s}$ particle) and $\mathrm{N}$ the soot particle concentration (particles $/ \mathrm{m}^{3}$ ).

(3) Soot particle production rate from nuclei

$\frac{d N}{d t}=(a-b . N) . n \quad$ (particles $\left./ \mathrm{m}^{3} \mathrm{~s}\right)$

where $a=3.5 \times 10^{8} / \mathrm{s}, b=8 \times 10^{-14} \mathrm{~m}^{3} / \mathrm{s}$-particle.

The numerical values of the constants in equations (13) to (15) above are from Ahmed et.al. ${ }^{18}$

The soot formation mechanism is considered to apply in each computational cell, and is consistent with the large scale mixing $(k-\varepsilon)$ which will control residence time of fuel rich eddies within the high temperature regions of the fuel spray domain, where thermal decomposition will occur. Extensive studies with the above formation scheme indicate an inadequate sensitivity to increases in engine swirl and hence higher air entrainment rates. To overcome this the soot formation scheme was not implemented until local molal ratio $\mathrm{C} / \mathrm{O} \geq 0.6$. Justification for this was based on the work of Wagner ${ }^{19}$.

SOOT OXIDATION MODEL -The model adopted is that of Magnussen and Hjertager ${ }^{13}$, where the oxidation rate of the soot is considered to follow that of the main combustion reaction, $\mathrm{B}(\varepsilon / \mathrm{k})$, with the controlling concentrations being either the partial density of the soot $\rho_{s}$ or that of soot oxidised by available oxygen, $\left(\rho_{O Z} / r_{s}\right) \cdot\left(\rho_{s} r s /\left(\rho_{s} r_{s}+\rho_{f} r\right)\right)$ where $r_{s}$ is the stoichiometric coefficient for soot (carbon). The soot oxidation rate per unit volume is thus:

$$
\dot{R_{S}{ }^{\prime \prime}}=B(\varepsilon / k) \cdot \min \left[\rho_{s},\left(\rho_{o 2} / r_{s}\right) \cdot\left(\rho_{s} r_{s} /\left(\rho_{s} r_{s}+\rho_{f} r\right)\right]\right.
$$

The number of radical nuclei reduced by the combustion process is

$$
\left.R_{n}{ }^{m}=R_{s}{ }^{m}\left(n / \rho_{s}\right) \quad \text { (particles } / \mathrm{m}^{3} \mathrm{~s}\right)
$$

The partial density of soot $\rho_{S}$ is determined from

$$
\rho_{s}=f_{v} \cdot \rho_{p} \quad\left(\mathrm{~kg} / \mathrm{m}^{3}\right)
$$

where $f_{v}$ is the volume fraction of soot $=N\left(\pi \mathrm{D}_{\mathrm{p}}^{3 / 6}\right), \mathrm{D}_{\mathrm{p}}$ being the diameter of a single soot particle, assumed to be $200 \AA$. The density of soot particles $\rho_{p}$ is taken as $2000 \mathrm{~kg} / \mathrm{m}^{3}$. We differ from Magnussen and Hjertager $^{13}$, and assume soot oxidation is confined to the Kolmogorov structure of the flow field, where soot 
and oxygen are considered well mixed and at high temperatures. This requires that the right hand side of equations (16) and (17) be multiplied by $m_{f}$ (equation 2).

\section{THE THERMAL RADIATION MODEL}

Approximately $30 \%$ of the heat loss in diesel engines is by thermal radiation 5 . Therefore for an accurate simulation of diesel engine combustion it is necessary to include radiation transfer in the calculation process.

The radiation transfer equation in a medium having absorption coefficient $\mathrm{K}$ is given by

$$
d l / d s=K \sigma T^{4} / \pi \quad-K I
$$

where $l$ is the radiation intensity in a general direction $\Omega$, S the distance in the direction $\Omega, \sigma$ the StefanBoltzmann constant and $T$ the temperature of the gas and soot mixture. As soot particles are generally small enough for scattering to be negligible, scattering terms have been neglected from the above equation.

A number of numerical techniques exist for calculation of radiative transfer in combustion systems. Those include Hottel's zone method ${ }^{20}$, flux methods 21 , Monte Carlo techniques 22 and the nonequlibrium diffusion method ${ }^{23}$. Alternative to these methods is the Discrete Transfer method of Lockwood and Shah ${ }^{24}$, which has rapidly become popular in various numerical combustion prediction applications ${ }^{25-29,32}$. The discrete transfer method combines the best features of zone, Monte Carlo and flux methods, while avoiding their shortcomings, and has been successfully used and validated in various combustion predictions ${ }^{24-29}$. The discrete transfer method is particularly useful in engine cylinder configurations as the method is applicable to arbitrary shaped geometries, boundary conditions can be easily accommodated, and it is computationally economical.

The method uses the control volumes in finite difference flow calculations and the procedure involves tracing rays in the calculation domain. Integration of equation (19) leads to a recurrence relation

$I_{n+1}=E[1-\exp (-K \delta s)]+I_{n} \exp (-K \delta s)$

which is used to calculate the unknown intensity at location $(n+1)$ from the known value at $(n)$, these two being separated by a step length $\delta s$. In equation (20) $E=K \sigma T^{4} / \pi$. Equation (19) is solved in discretised solid angle elements within which the intensity is assumed to be uniform. The temperature and absorption coefficients are taken as uniform over $\delta$ s. Along a path of a ray the recurrence relation $(20)$ is applied repeatedly to calculate the total intensity of incident radiation at the end point of the ray. Inhomogeneities of the flow field are taken into account by using local temperatures and absorption coefficients in each control volume, in applying the recurrence relation. A full description of the method can be found in ${ }^{24}$.

THE CALCULATION OF tHERMaL Radiative PROPERTIES - Estimation of radiative properties of the gaseous products of combustion is important to the calculation of correct radiative heat transfer. In this case $\mathrm{CO}_{2}, \mathrm{H}_{2} \mathrm{O}$ and smoke (soot) are the main participating species. Here total emissivity of the mixture in each control volume is calculated using the 'mixed grey and clear gas formulation' of Hottel and Sarofim ${ }^{20}$. In many predictions of furnace heat transfer and combusting situations the use of the mixed grey concept has been found to work well $26,28,29$. In the present study the constants and weighting coefficients determined by Truelove ${ }^{30}$ are employed to calculate the total gas emittance $\varepsilon$ given by

$\varepsilon=\sum_{i=1}^{n} a_{g, i}\left[1-\exp \left(-K_{g, i} P_{g, i}-K_{s, i} C\right) L\right]$

where $P_{g, i}$ is the partial pressure of an absorbing participating gas ( $\mathrm{i}=\mathrm{CO}_{2}$ or $\left.\mathrm{H}_{2} \mathrm{O}\right), K_{g, i}$ is the absorption coefficient of that gas, $K_{s, i}$ is the volumetric soot absorption coefficient, $C$ is the soot concentration and $L$ is the mean path length which is set to the discretised distance $\delta s$ in equation. (20). The influence of temperature is accommodated in the weighting coefficients specified by Truelove ${ }^{30}$. The value of $K$ is then obtained from the relation

$$
\varepsilon=1-\exp (-K \delta s)
$$

The discrete transfer method can be readily extended to incorporate a more elaborate treatment of radiative properties such as the RADCAL algorithm of Grosshandle ${ }^{31}$ or the wide band model described by Docherty and Fairweather ${ }^{32}$.

\section{ENGINE CONFIGURATION AND COMPUTATIONAL REPRESENTATION}

Economy of computational resources has dictated an axisymmetric combustion chamber in the piston bowl with a cylindrical disc configuration of $55 \mathrm{~mm}$ diameter and $19 \mathrm{~mm}$ depth. The cylinder bore of the engine is $102 \mathrm{~mm}$. The fuel injection nozzle is considered to lie on the engine cylinder axis and to protude $3 \mathrm{~mm}$ into the cylinder. The nozzle has four orifices of $0.27 \mathrm{~mm}$ diameter, oriented to provide spray centreline axes at an angle of $15^{\circ}$ from the cylinder head inner surface.

The engine is normally aspirated and running conditions chosen to coincide with experimental data by Dent and Suliaman ${ }^{5}$ on a similar engine but with an offset combustion chamber. The operational data set used in the simulation here is: Engine speed 1750 r.p.m., Fuel quantity injected per engine cycle $0.026 \mathrm{~g}$. 
representing $40 \%$ of full load, compression ratio $15: 1$, injection timing $18^{\circ}$ b.t.d.c., air swirl at $90^{\circ}$ b.t.d.c. is 3500 r.p.m. and fuel is assumed to be Dodecane $\left(\mathrm{C}_{12} \mathrm{H}_{26}\right)$. For the simulation a $90^{\circ}$ sector was used for combustion studies with up to 3450 computational cells, all wall surfaces were assumed to remain at a constant temperature of $400 \mathrm{~K}$. For radiation calculations wall emissivity was assumed to be 0.8 .

\section{RESULTS AND DISCUSSION}

Averaging over all computational cells in the cylinder provided mean values of: cylinder pressure, net soot concentration, gas temperature and heat release rate, at fixed crank angles of the engine cycle. These data are shown in Fig. 1 which can be used as a reference against which data in subsequent figures may be compared.

In Fig. 2 a perspective view of the combustion chamber at a crank angle of $15^{\circ}$ b.t.d.c. (before top dead centre) is shown. The deflection of the injected fuel sprays by the swirling air flow is apparent, and the recirculation region in the wake of the sprays is clearly seen in the velocity vector field in the plane just above the combustion chamber which is also shown.

Assuming that the soot generation and oxidation processes cease at exhaust valve opening (EVO) and by considering an expansion to ambient temperature and pressure, the mass of soot in the

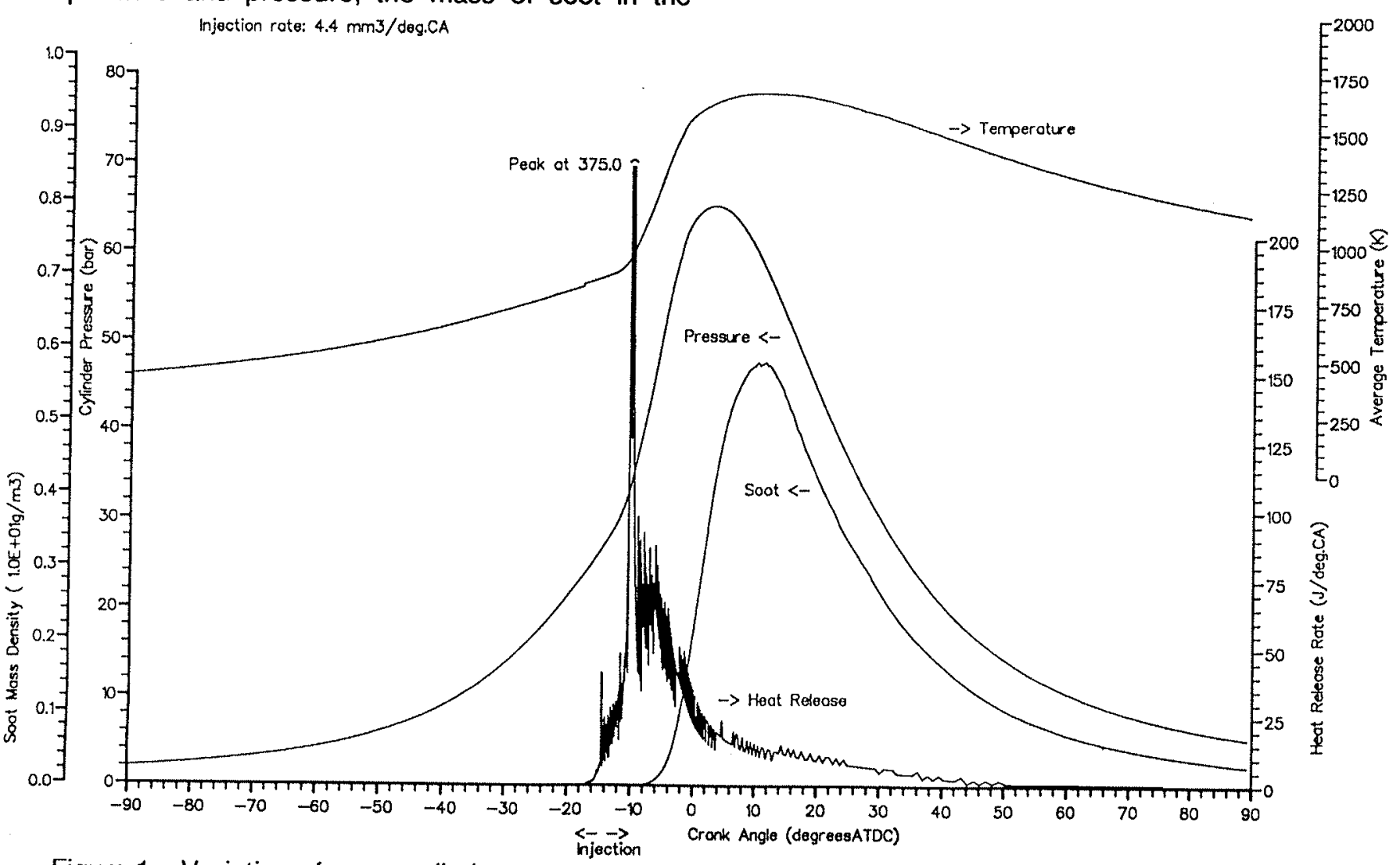

Figure 1. Variation of mean cylinder pressure, gas temperature, net soot concentration and heat release rate.
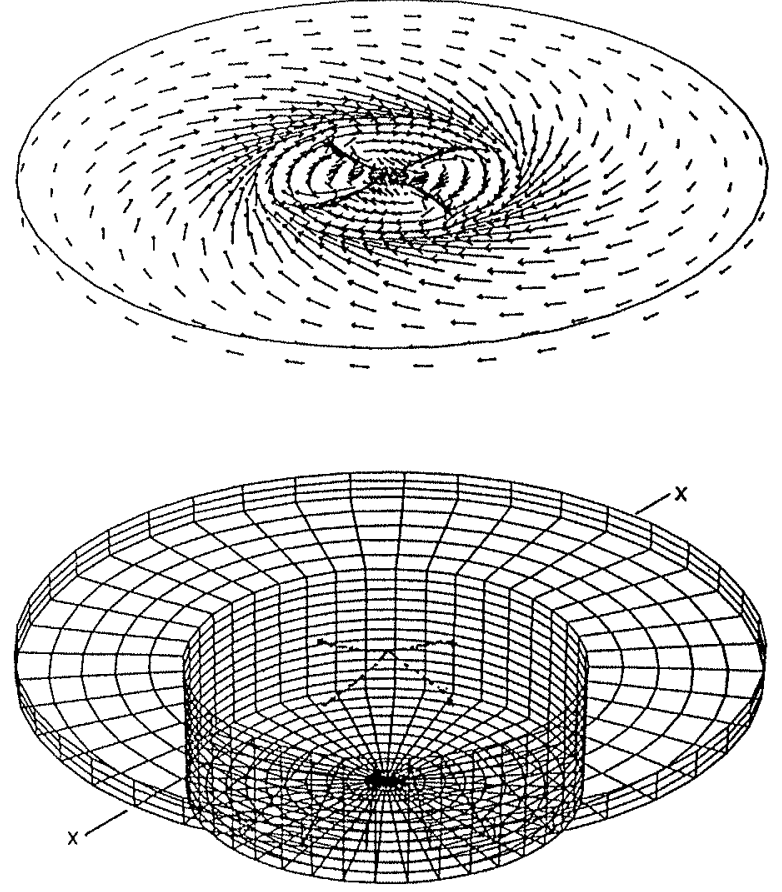

Figure 2. Combustion chamber geometry at $15^{\circ}$ b.t.d.c, spray deflection by air swirl and the velocity field of air flow just above combustion chamber. 
cylinder at EVO can be used to estimate the amount of smoke in the exhaust gases. In terms of Bosch number, the predicted value for EVO at $135^{\circ}$ a.t.d.c. is 1.2 which is of the expected order of magnitude for an operational engine of this type.

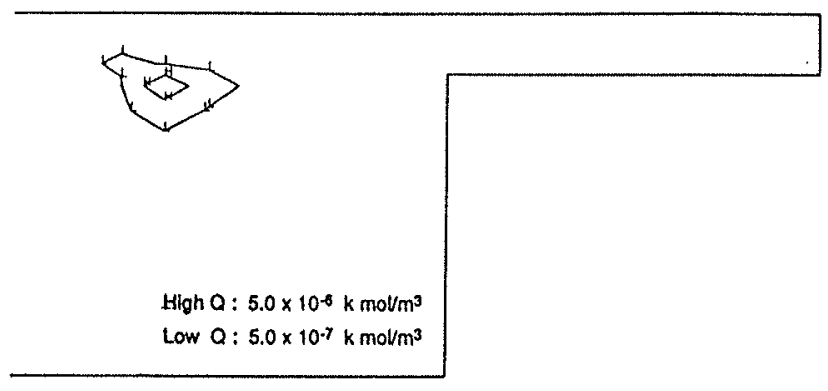

(a)

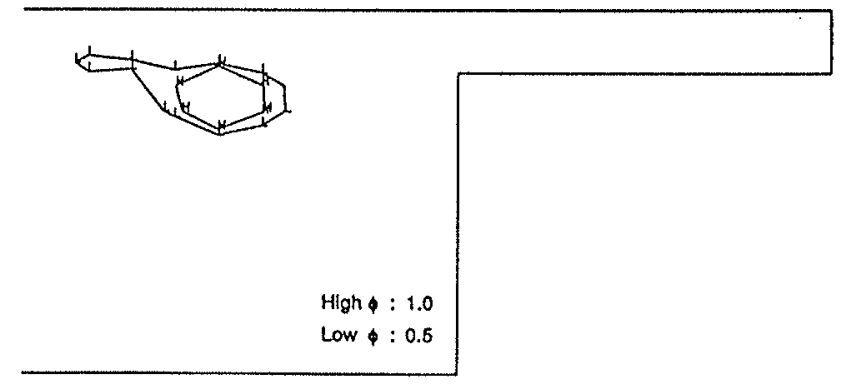

(b)

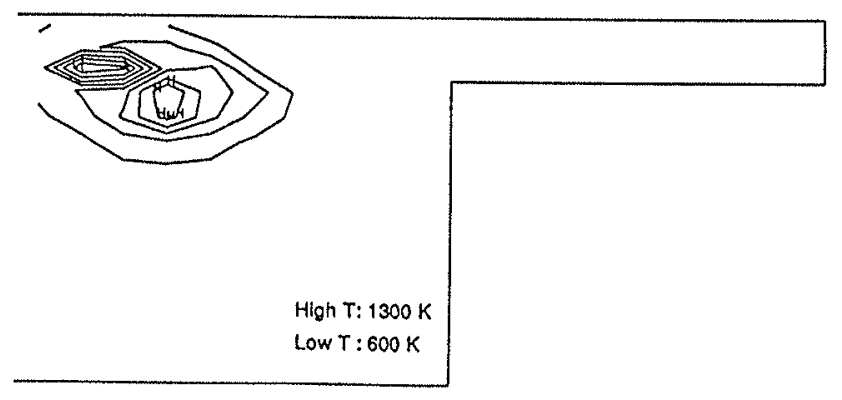

(c)

Figure 3 (a) Contours of labile intermediate $Q$ in the plane $X-X$ at $15^{\circ}$ b.t.d.c.

(b) Contours of fuel/air equivalence ratio $\phi$ in the plane $X-X$ at $15^{\circ}$ b.t.d.c.

(c) Contours of gas temperature in the X-X plane at $15^{\circ}$ b.t.d.c.

Figure 3 shows contours in the diameteral plane $X-X$ of Figure 2 at crank angle $15^{\circ}$ b.t.d.c, for labile intermediate $Q(3 a)$, equivalence ratio $\phi(3 \mathrm{~b})$ and temperature (3c). The highest and lowest values of each contour are indicated by $H$ and $L$ respectively.
The $\mathrm{H}$ contour for $\mathrm{Q}$ represents a well mixed region of the spray plume downstream of the jet axis; a temperature contour of $1300 \mathrm{~K}$ passes through this region which is progressing rapidly to autoignition. The contours of $\phi=1$, and gas temperature $(H)$ and $(L)$, illustrate the dependence of autoignition on chemically correct stoichiometry and high temperature, which concur with experimental mixing studies and high speed photography of engine combustion undertaken by Morris and Dent ${ }^{33}$.

Figures 4(a) and 4(b) show comparisons between computed and experimental radiative flux at two points on the cylinder head, located at $6 \mathrm{~mm}$ and $38 \mathrm{~mm}$ radius from the cylinder centreline respectively. In Figure 4(a) the computed peak flux is approximately that measured, but the rise to peak value occurs earlier. The additional delay to the heat release in the experimental engine was due to the non-optimal location of its injector. Constraints on the design of the cylinder head meant that the injector had to be sited such that two of the sprays impinged heavily on the sides of the combustion chamber.

In Figure 4(b) radiative fluxes are lower due to the restricted view the detector has of the combustion chamber, particularly near top dead centre (t.d.c). As the piston moves into the expansion stroke, the view of the chamber space is improved but not significantly, so radiation flux is low. At $90^{\circ}$ after t.d.c., the flame temperature has decreased significantly due to expansion, so that improved view of the combustion space is of little consequence. The experimental results in 4 (b) show earlier rise in the radiative heat flux compared with computation. This is due to the offset of the injector towards the detector at radius $38 \mathrm{~mm}$. Two fuel sprays now impinge heavily on the combustion chamber wall near the detector and probably cause combustion products to spill over the top of the piston, enabling early detection by the radiation sensor.

Comparisons of measured and computed convective heat fluxes are not shown as it is known ${ }^{34,35}$ that the law of the wall formulation significantly under predicts peak heat flux as we observed. Also, the phasing of the flux is governed by the rate of heat release in the cylinder ${ }^{35}$ which is not accounted for in the law of the wall formulation.

Figure 5(a) shows a contour plot of computed radiative flux on the cylinder head at $10^{\circ}$ a.t.d.c. High radiative fluxes down stream of the fuel spray, and adjacent to the combustion chamber wall are apparent. These are zones of high fuel concentration and temperature, which also result in high soot concentration as can be seen in Figures 5(b), (c) and (d), which are contours in the plane $1.5 \mathrm{~mm}$ below the top of the piston crown. The peak in the net radiative flux to the cylinder head occurs close to the region of highest soot concentration. The two regions are not 


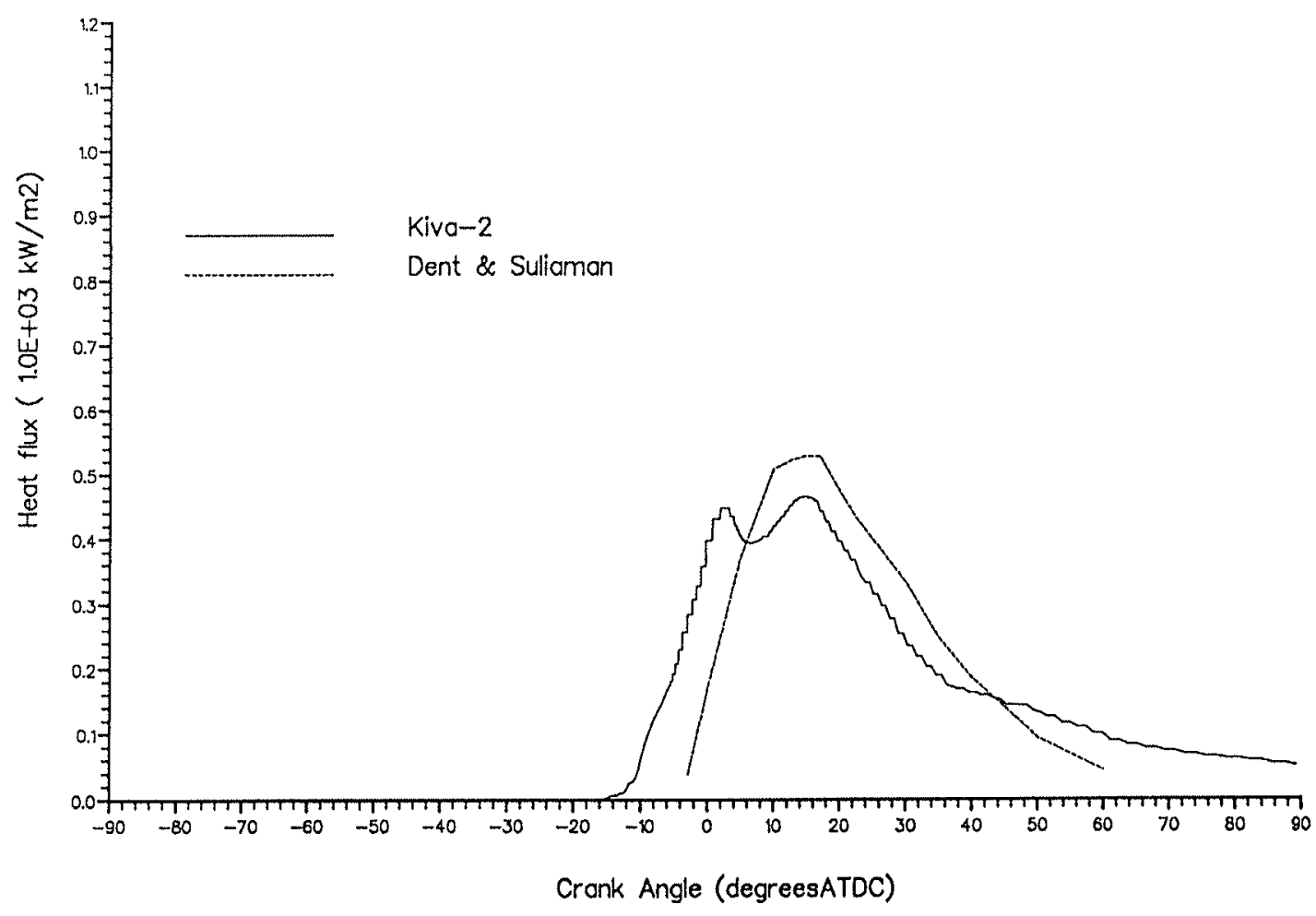

Figure 4(a) Comparison between computed and measured radiative heat flux at location R1 on cylinder head.

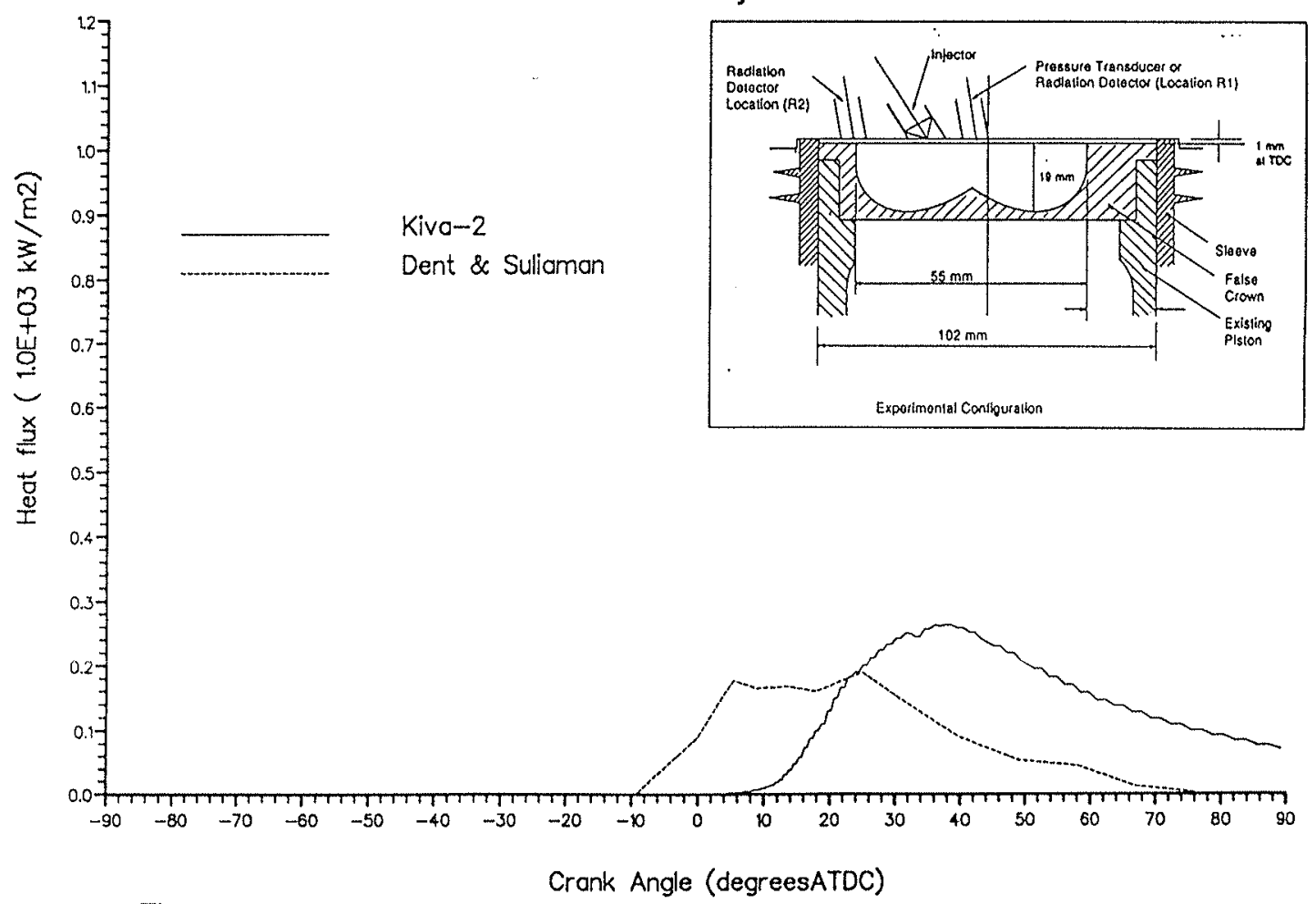

Figure 4(b) Comparison between computed and measured radiative heat flux at location $\mathrm{R} 2$ on cylinder head.

exactly coincident as the radiative flux to a point on the cylinder head above the combustion chamber is a summation of contributions from all parts of the chamber. It is important to note the localised nature of the soot distribution and temperature which results from the dispersion of the fuel by the action of swirt and squish as evidenced by a comparison of Figure 2 and Figures 5(b), (c) and (d). Strong localisation of 


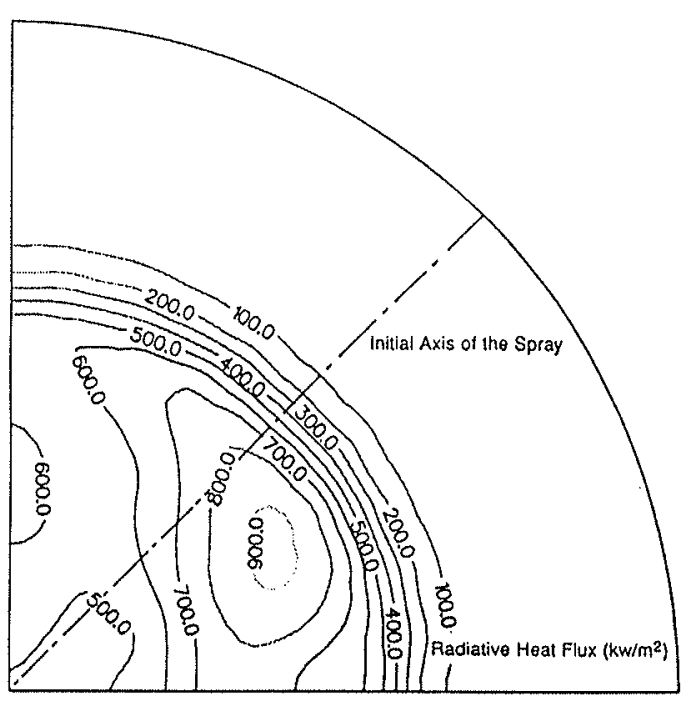

(a)

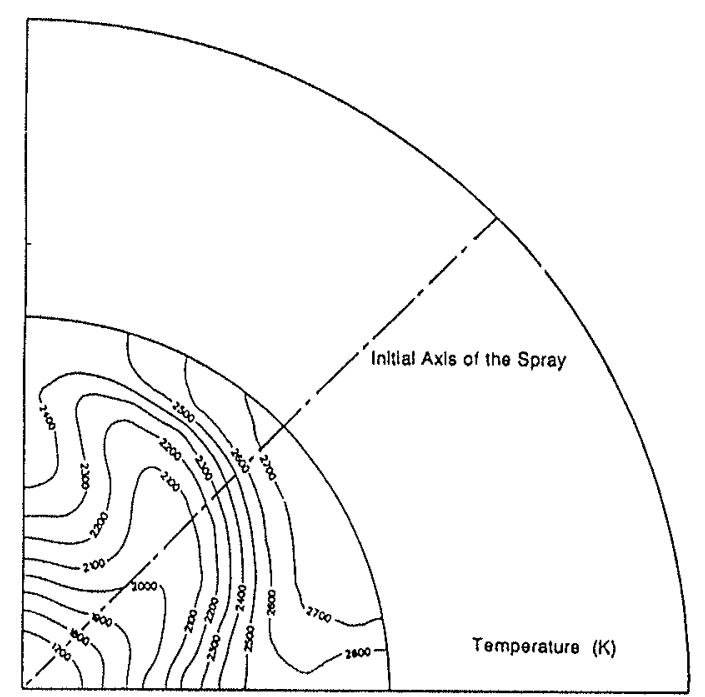

(c)

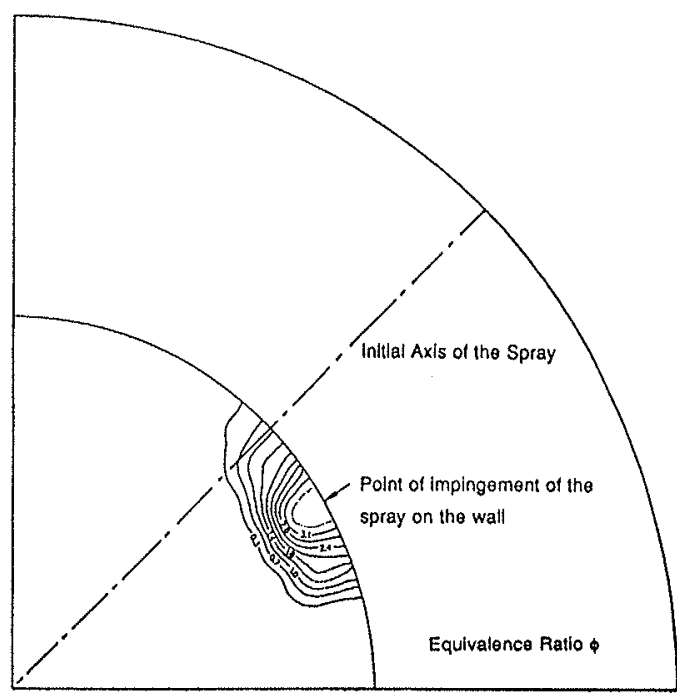

(b)

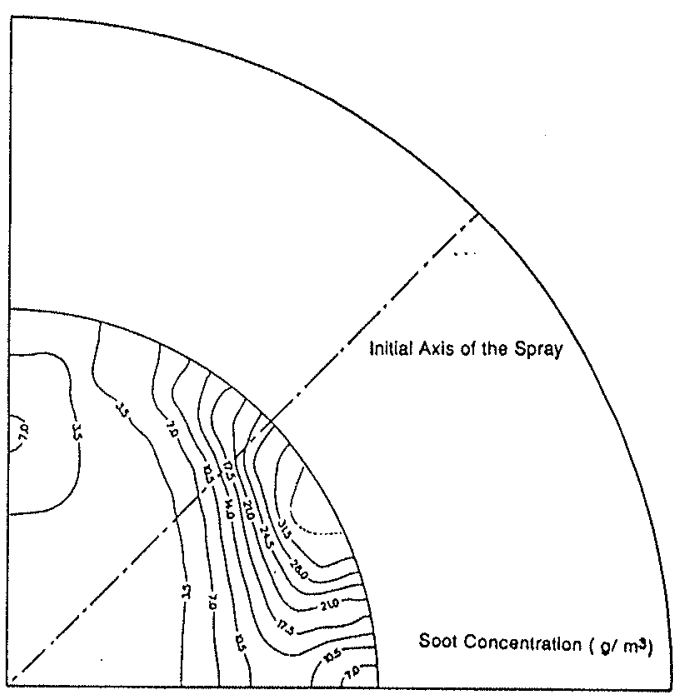

(d)

Figure 5 (a) Contours of radiative heat flux to cylinder head at $10^{\circ}$ a.t.d.c.

(b) Contours of equivalence ratio $(\phi)$ in a plane $1.5 \mathrm{~mm}$ below the piston crown at $10^{\circ}$ a.t.d.c.

(c) Contours of temperature in a plane $1.5 \mathrm{~mm}$ below the piston crown at $10^{\circ}$ a.t.d.c.

(d) Contours of soot density in a plane $1.5 \mathrm{~mm}$ below the piston crown at $10^{\circ}$ a.t.d.c.

soot concentration has been experimentally observed by Zur Loye et. $\mathrm{al}^{36}$, and inferred from the measurement of particulate radiant emission by Yan and Borman ${ }^{37}$.

This point can be further illustrated by plotting the integrated value of the product of the radiation absorption coefficient and optical path length $(\mathrm{KL})$ in the axial direction of the computation space, for selected cells and sectors of the combustion chamber. The mass averaged temperature and over the same integration path as $\mathrm{KL}$, for the same sectors and cells was also computed. Figure 6 shows such results as a function of crank angle, where $\mathrm{KL}$ varies from zero just before the onset of combustion to a maximum value of about 2.5 in sector 5 cell 4 at about $10^{\circ}$ a.t.d.c., dropping sharply to about 0.4 for all cells and sectors from about $20^{\circ}$ a.t.d.c. up to the end of the computation at $90^{\circ}$ a.t.d.c. $\mathrm{KL}$ values in cell 4 , sector 5 decrease from 2.5 at $10^{\circ}$ a.t.d.c to 1.4 in sector 1 at $15^{\circ}$ a.t.d.c, showing the effect of swirl. The magnitude of peak KL is similar to that measured by $Y$ an and Borman $^{37}$. The constancy of $\mathrm{KL}$ at about 0.4 for all 

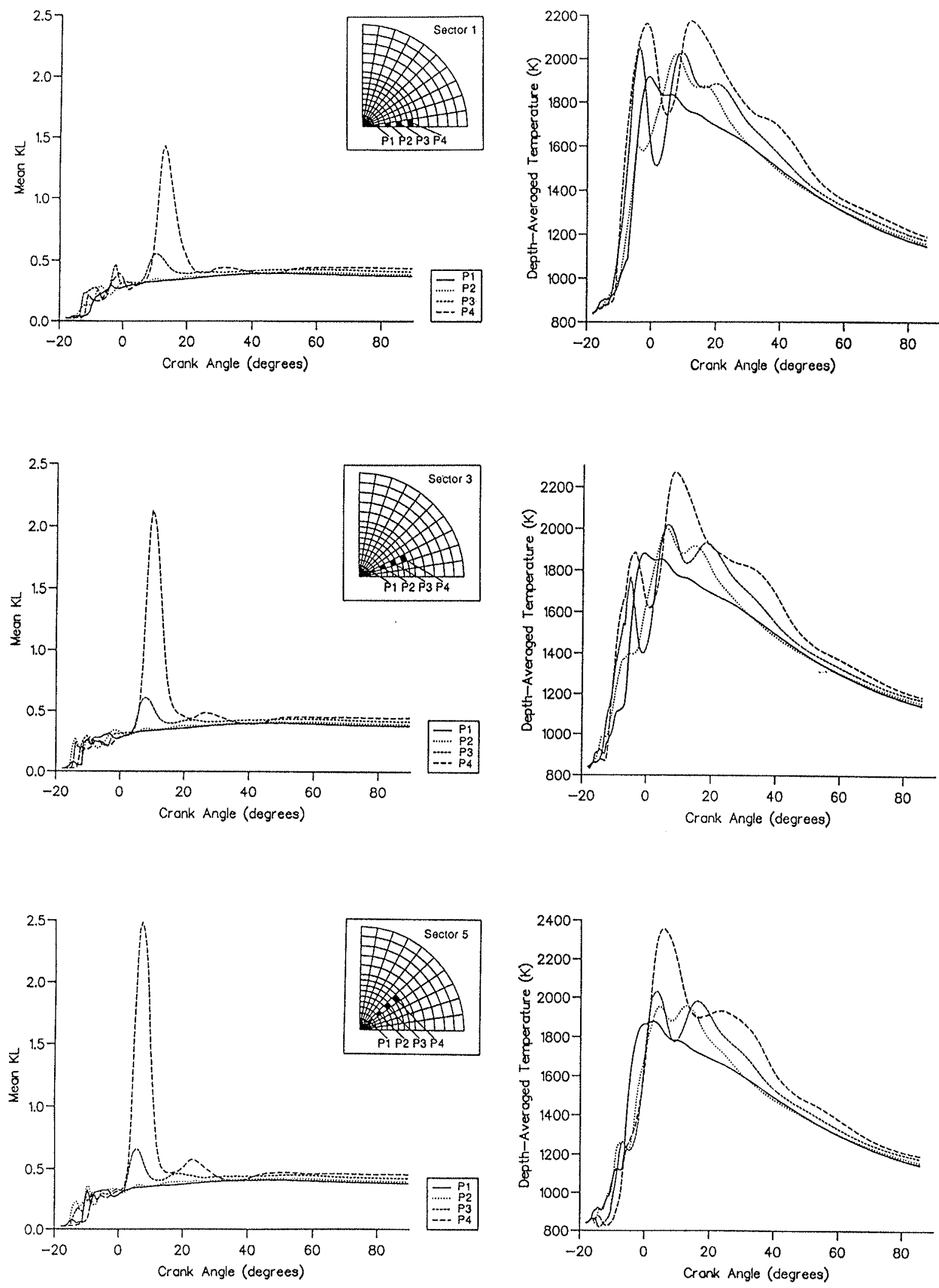

Figure 6 (a) Depth averaged KL and temperature values at points shown in inset (sector 1)

(b) Depth averaged $\mathrm{KL}$ and temperature values at points shown in inset (sector 3 )

(c) Depth averaged KL and temperature values at points shown in inset (sector 5) 
cells and sectors after $20^{\circ}$ a.t.d.c. appears to be mainly due to the non luminous component of the radiation, the decreasing effect of cylinder temperature experimental observations, and with the dispersion of the fuel by the interaction of the injected fuel sprays with the air swirl.

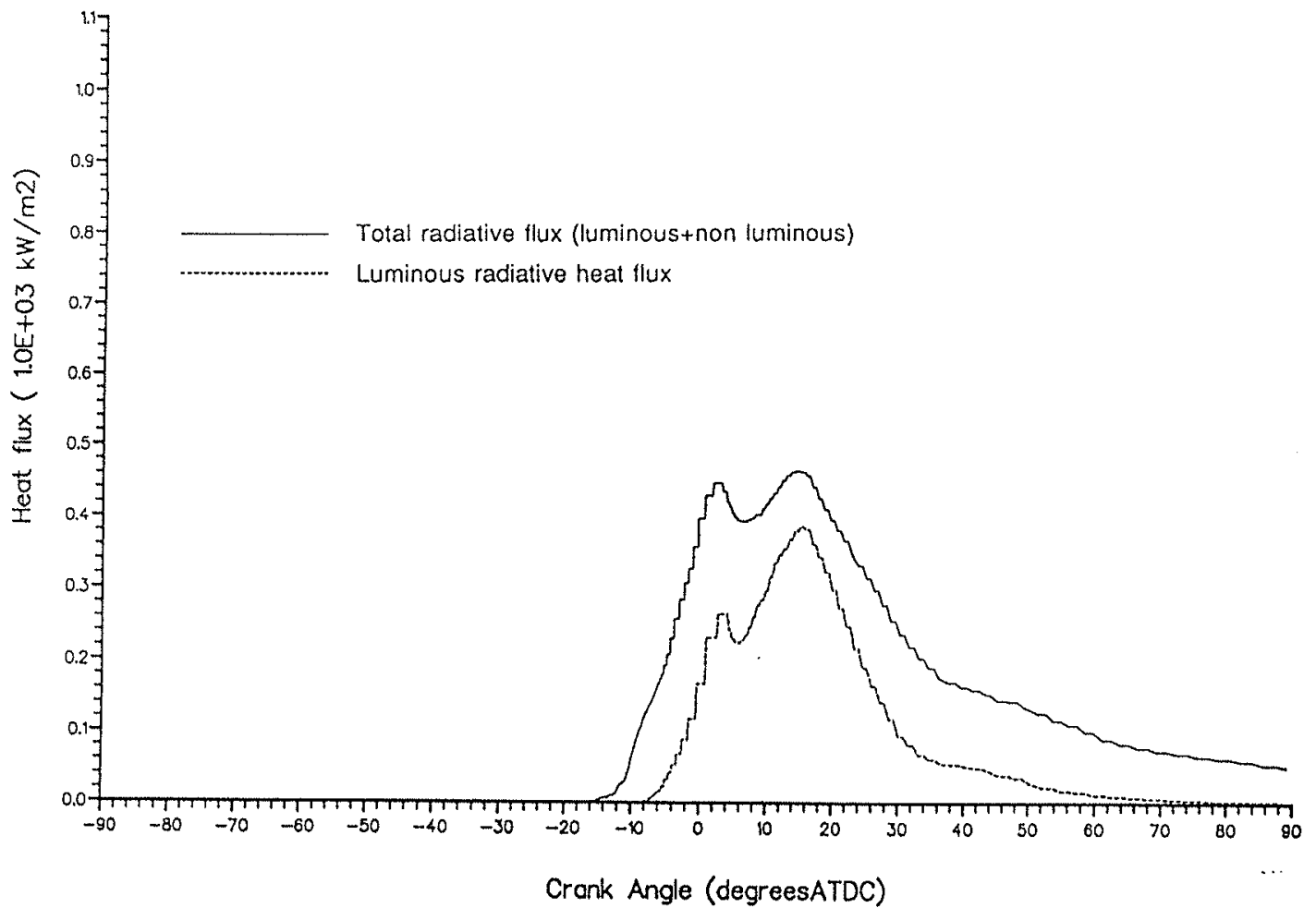

Figure 7. Predicted total (luminous+non luminous) and luminous radiative flux at location $\mathrm{R} 1$ versus crank angle.

being compensated for by increase in optical path length due to downward movement of the piston. This is illustrated in Figure 7 where the computed total and luminous radiation heat fluxes at $\mathrm{R} 1$ are plotted as a function of crank angle. The magnitude and variation of the temperature across the combustion bowl radius is as expected, being lowest in the centre of the bowl and highest at the edge. Significant variations in temperature at the edge of the bowl is observed due to dispersion of the fuel by the air swirl. The magnitude of the temperatures in Figure 6 are similar to those observed experimentally by $Y$ an and Borman ${ }^{37}$ and more particularly by Aoyagi et al..$^{38}$ and Kamimoto ${ }^{39}$ in swirl assisted engines.

\section{CONCLUSIONS}

Application of the discrete transfer model for thermal radiation in the engine CFD code KIVA with established sub models for engine autoignition and soot formation and oxidation, has been shown to give results which are consistent with direct measurements of thermal radiation in diesel engines. The localised nature of soot concentration in the combustion space as indicated by computation is consistent with

\section{ACKNOWLEDGEMENTS}

We wish to express our appreciation of support received in the course of this work from the Science and Engineering Research Council of the United Kingdom and Ford Motor Company for assistance with computational resources.

\section{REFERENCES}

1. Amsden, A. A., O'Rourke, P. J. and Butler, T. D.: KIVA II A Computer Program for Chemically Reactive Flows with Sprays, Los Alamos National Laboratory Report LA-11560-MS, May 1989.

2 Amsden, A. A., Butler, T. D. and O'Rourke, P. J.: The KIVA II Computer Program for Transient Multdimensional Chemically Reactive Flows with Sprays, S.A.E. Paper No. 872072 (1987).

3 Amsden, A. A., Ramshaw, J. D., O'Rourke, P. J. and Dakowicz, J. K. : KIVA: A Computer Program for Two and Three Dimensional Fluid Flows with Chemical Reactions and Fuel Sprays", Los Alamos National Laboratory Report LA-10245-MS, February 1985. 
4 Amsden, A. A., Butler, T. D., O'Rourke, P. J. and Ramshaw, J. D. :"KIVA: A Comprehensive Model for 2D and 3D Engine Simulations", S. A. E. Technical Paper No. 850554 (1985).

5 Dent, J. C. and Suliaman, S. J.: 'Convective and Radiative Heat Transfer in a High Swirl direct Injection Diesel Engine", S. A. E. Paper No. 770407 (1977).

6 Naber, J.D and Reitz, R.D, 'Modelling Engine Spray/Wall impingement', S.A.E Paper No. 880107 (1988).

7 Chomiak, J.: Sixteenth Symposium (International) on Combustion, pp. 1665-1673, The Combustion Institute, 1976.

8 Magnussen, B. F. : Particulate Carbon Formation During Combustion (D.C.Siegla and G. W. Smith, Eds.), pp321-341, Plenum Press, N.Y., 1981.

9 Theobold, M. A. and Cheng, W. K. : A Numerical Study of Diesel Ignition", A.S.M.E Paper No. 87-Fe2 (1987).

10 Schapertons, H. and Lee, W.: 'Multidimensional Modelling of Knocking Combustion in S. I. Engines", S. A. E. Paper No. 850502.(1985).

11 Halstead, M.P., Kirsh, L. J. and Quinn, C. P. Comb. Flame, 30, pp.45-60 (1977).

12 Hirst, S. L. and Kirsch, L. J. :"The Application of a Hydrocarbon Autoignition Model in Simulating Knock and Other Engine Combustion Phenomena", Combustion Modelling in Reciprocating Engines ( $\mathrm{J}$. N. Mattavi and C. A. Aman, Eds.),pp.193-229, Plenum Press, N.Y., 1980.

13 Magnussen, B. F. and Hjertager, B. H.: Sixteenth Symposium (International) on Combustion, pp.719727, The Combustion Institute, 1976.

14 Dent, J. C., Mehta, P. S. and Swan, J.: "A Predictive Model for Automotive D.I. Diesel Engine Performance and Smoke Emissions", I.Mech.E. International Conference - Diesel Engines for Passenger Cars and Light Duty Vehicles, London 1982.

15 Kyriakides, S.C., Dent, J. C. and Mehta, P. S.: "Phenomenological Diesel Combustion Model Including Smoke and NO Emission", S.A.E. Paper No. 860330 (1986).

16 Zellat, M., Rolland, T. and Poplow, F.: "Three Dimensional Modelling of Combustion and Soot Formation in an Indirect Injection Diesel Engine", S. A. E. Paper No. 900254 (1990).

17 Tesner, P. A., Snegiriova, T. D. and Knorre, V. G., Comb. Flame, 17, pp.253-260 (1971).

18 Ahmed T., Plee, S.L. and Myers, J.P., Computation of Nitric Oxide and Soot emissions from steady turbulent spray and jets, General Motors, Research Report EN31, 1981.

19 Wagner, H.Gg.,'Soot Formation- An Overview', Particulate Carbon Formation During Combustion,
Editors Donald C. Siegla and George W. Smith, Plenum Press, 1981.

20 Hottel H.C. and Sarofim A. F. 'Radiative transfer, 1967, McGraw Hill, New York.

21 Viskantha, R. and Mengüç, M. P.(1987), Prog. in Energy and Comb. Sci. Vol 13, pp97-160.

22 Stewart, F. R, and Cannon, P.: Int. J. Heat Mass Transfer, 14,pp. 245-262 (1971).

23 Ascot, J. A., Gibb, J. and Jenner, R.: Combustion Institute European Symposium, p674, Academic Press, N. Y., 1973.

24 Lockwood, F. C. and Shah N. G.: Eighteenth Symposium (International) on Combustion, pp 1405-1414, The Combustion Institute, 1981.

25 Gosman A. D. , Lockwood, F.C., Megahed, I. E. A. and Shah, N. G., Proc. 18th Aerospace Sciences Meeting, Paper 80-0016, Pasadena, Jan. 1980.

26 Abbas, A. S., Lockwood, F. C. and Salooja A. P. Comb.Flame, 58, 91 (1984).

27 Jeng, S. M. and Faeth, G. M., Trans. ASME, Journal of Heat Transfer, 106, 886 (1984).

28 Lockwood F. C. and Malalasekera W. M. G. and Papadopoulos, C.: "Steel and Glass Furnace Modelling", Conference on Applied Energy, Swansea, p341, Institute of Energy (1989).

29 Lockwood, F. C. and Malalasekera, W. M. G.: Twenty Second Symposium...(International) on Combustion, pp1319-1328, The Combustion Institute, 1988.

30 Truelove, J. "A Mixed Grey Model for Flame Radiation", UK AERE, Harwell report HL76/3448, 1976.

31 Grosshandler, W.L., Int. J. Heat Mass Transfer, 23, p 1447 (1980).

32 Docherty P. and Fairweather M., Comb and Flame, 71, p79-87 (1988).

33 Morris, C. J. and Dent, J. C. : The Simulation of Air Fuel Mixing in High Swirl Open Chamber Diesel Engines, Proc I.Mech.E, Vol 190, pp47-76 (1976).

34 Kuo T-W and Reitz R. D (1989), "Computation of Premixed charge combustion in Pancake and Pentroof Engines", SAE International Congress and Exposition, Detroit, Michigan USA, Feb. 27 - Mar 3, 1989.

35 Kang, Y.H., Chang, I.P and Martin J.K.(1990), 'Comparison of Boundary Layer Treatments for Heat Transfer in IC Engines', SAE International Congress and Exposition, Detroit, Michigan USA, Feb. 26 - Mar 2, 1990.

36 Zur Loye, A.O., Siebers, D.L. and Dec, J.F. (1990),2 -D Soot Imaging in a Direct Injection Diesel Engine Using Laser Induced Incandescence', Comodia 90- Proceeding of the International Symposium on Diagnostics and Modelling of Combustion in Internal Combustion Engines, Sept. 3-5, Kyoto, Japan, 1990. 
37 Yan, J, and Borman, G.L., 'Analysis and In-Cylinder Measurement of Particulate Radiant Emissions and Temperature in a Direct Injection Diesel Engine', Paper No:881315, S.A.E. Trans., Vol6, pp1632$1644,1988$.

38 Aoyagi, Y, Kamimoto, T., Matsui, Y. and Matsuoka, S. 'A Gas Sampling Study on the Formation Processes of Soot and NO in a DI Diesel Engine', $\mathrm{SAE}$ International Congress and Exposition, Detroit, Michigan USA, Feb. 25 - 29, 1980.

39 Kamimoto, T., Aoyagi, Y., Matsui, Y. and Matsuoka, S. , 'The Effects of Some Engine Variables on Measured Rates of Air Entrainment and Heat Release in a DI Diesel Engine', SAE International Congress and Exposition, Detroit, Michigan USA, Feb 25 - 29, 1980. 